\title{
Antiviral immune response and the route of infection in Drosophila melanogaster
}

Juan A. Mondotte and Maria-Carla Saleh

Institut Pasteur, Viruses and RNA Interference Unit, CNRS Unité Mixte de Recherche 3569, 75724 Paris Cedex 15, France.

\begin{abstract}
The use of Drosophila as a model organism has made an important contribution to our understanding of the function and regulation of innate immunity in insects. Indeed, insects can discriminate between different types of pathogens and mount specific and effective responses. Strikingly, the same pathogen can trigger a different immune response in the same organism, depending solely on the route of infection by which the pathogen is delivered. In this review, we recapitulate what is known about antiviral responses in Drosophila and how they are triggered depending on the route and the mode used for the virus to infect its host.
\end{abstract}

\section{Introduction}

Insects are found in almost every environment on Earth. They are the largest and most diverse group of animals and are crucial components of many ecosystems where they participate in functions as diverse as plants pollinators or control of other insects and plant pests. Insects have economic 
importance: some produce useful substances, such as honey, wax, and silk (Foottit and Adler, 2009, Gullan and Cranston, 2010, Hill, 1997), but insects also cause severe economic losses by damaging crops and food production (Hill, 1997). In addition, some insects pose an increasing menace to human and animal health. Insects such as mosquitoes, lice, fleas and bed bugs are able to transmit a number of disease-causing pathogens such as viruses, bacteria, protozoa and nematodes (Baxter et al., 2017). Over one million people worldwide die from mosquito-borne diseases every year. Zika virus, West Nile virus, chikungunya virus, dengue virus, and Plasmodium falciparum (the causative agent of malaria) are examples of pathogens that are spread to people by mosquito bites (WHO, 2016).

Successful insect management requires intervening at some point during the insect's life cycle before they bite and infect a human or an animal. To achieve this, great efforts have been made in the recent years to understand the immune response in insects and how insects cope with a pathogen infection. To survive in a world full of microorganisms and parasites, insects developed potent defense mechanisms that depend on innate immunity. Most of our knowledge on insect innate immunity comes from studies performed on the fruit fly, Drosophila melanogaster. Fruit flies have a well-established genetic toolbox, are easy and inexpensive to culture in laboratory conditions and have been the model insect of choice for the past hundred years (Jennings, 2011).

Studies of innate immunity in Drosophila initially focused on bacterial and fungal infection, and revealed that the production of antimicrobial peptides (AMPs) plays an important role in the host defense (Ganesan et al., 2011). 
Recently several groups started to investigate the genetic basis of the antiviral resistance in Drosophila. It is now well established that RNA interference (RNAi) plays a central role in the control of viral infections in insects, while other inducible responses and restrictions factors contribute to resistance to viral infections (Mussabekova et al., 2017).

Most studies performed to understand host-virus interactions in Drosophila have been done by actively delivering the virus by injection into the flies. Although this approach has been shown to be relevant for identifying pathogen virulence factors and host defense mechanisms, injecting the virus bypasses the hosts' natural protection barriers. Several studies showed that the route used by pathogens to infect their hosts has an important impact on the outcome of an infection and can trigger differential immune responses (Ferreira et al., 2014, Martins et al., 2013, Behrens et al., 2014, Gupta et al., 2017b). In humans, for instance, pathogens infecting hosts through wounded skin results in significantly higher cases of fatality than if the pathogens are inhaled or ingested (Leggett et al., 2012).

In addition, Drosophila, as well as mosquito, is a holometabolous insect, undergoing metamorphosis between four life stages, embryo, larva, pupa, and imago or adult (Figure 1A). Therefore, it could be postulated that depending on the route of infection of the pathogen and the developmental stage of the insect, the pathogen tropism and the infection outcome may be different.

This review is an attempt to cover the different elements of antiviral immunity in insects, with an emphasis on Drosophila and focusing in the different routes and modes of infections used to deliver the virus. 


\section{[insert Figure 1 here]}

Figure 1. Drosophila life cycle and routes of infection

(A): Drosophila exhibits complete metamorphism. The life cycle includes an embryo, larval forms, pupa and finally emergence as an adult.

(B): Potential routes of pathogen entry in Drosophila adult and larva. Each color depicts a physiological barrier breached by the pathogen during infection.

\section{Routes of infection}

To fight infections, insects rely on multiple innate defense reactions, many of which are shared with higher organisms. These reactions include the use of physical barriers together with local and systemic immune responses (Bergman et al., 2017).

Epithelia physically separate self from non-self and are the first line of defense against external pathogens. They fulfill the important task of preventing the penetration of pathogens that could cause systemic infections (Lemaitre and Hoffmann, 2007). The potential routes of pathogen entry in insects involve the penetration of pathogens through epithelium and are: through the cuticle, through the trachea, through the gut, and through the genital organ (Davis and Engstrom, 2012, Siva-Jothy et al., 2005) (Figure 1B).

\section{Through the cuticle}

The cuticle or exoskeleton is a protective integument over the external surface of insects. It is an extracellular matrix produced by the epidermis and consists mainly of proteins and the polysaccharide chitin (Tajiri, 2017). In addition to a physical barrier, the cuticle also provides an active biochemical barrier. When the epicuticle (outer layer of the cuticle) of a silkworm larva, was abraded in 
the presence of live bacteria or bacterial cell wall components, the AMP cecropin was detected in the underlying epithelial cells, indicating a highly localized antibacterial response (Brey et al., 1993). Direct penetration of intact cuticle is the normal route of entry by most entomopathogenic fungi (Lu and St Leger, 2016). Insects in the wild are often wounded by predators (Kanbar and Engels, 2003) or during mating (Lange et al., 2013), increasing the risk for systemic infections through the cuticle. It was shown that bacteria entering the hemocoel through the site of cuticle injury trigger a systemic immune response, which results in the synthesis and secretion of a large set of humoral effector molecules. This reaction mainly consists of AMP production by the fat body, the stress response proteins and factors required for phagocytosis and coagulation (Lemaitre and Hoffmann, 2007).

\section{Through the trachea}

The respiratory tract of insects is another possible route of pathogen entry. The tracheae consist of an epithelium monolayer that wraps around the central, gas-transporting lumen. Air enters the respiratory systems of insects through a series of external openings called spiracles and passes through primary, secondary and terminal branches, reaching all tissues in the body (Ghabrial et al., 2003).

The epithelial cells in the trachea not only constitute a physical barrier, but also the first line of defense against airborne pathogens. Infection with the baculovirus Autographa californica $\mathrm{M}$ nuclear polyhedrosis virus in Lepidoptera can be initiated on tracheae, and is disseminated within the host via the trachea (Kirkpatrick et al., 1994, Engelhard et al., 1994). 
In other insects such as Drosophila, the trachea is also a potential infection route, since the spiracles of larvae are in contact with potentially infectious organisms present in the food. Exposure of larva or adult flies to the gramnegative bacteria, results in the induction of the AMPs in the respiratory tract (Ferrandon et al., 1998, Tzou et al., 2000, Wagner et al., 2008).

\section{Through the gut}

Many insect species mainly feed on decaying or contaminated food and are thus exposed to very large quantities of microorganisms. The gut is a tubular epithelium composed of a monolayer of cells surrounded by visceral muscles and tracheae. The tube structure of the digestive tract can be divided into the foregut, midgut and hindgut. The midgut is the main site of digestion and food absorption and the one exposed to more pathogen threats. A semipermeable chitinous layer, the peritrophic matrix, protects the epithelium from physical damage and regulates the passage of particles between the lumen and the enterocytes (Linser and Dinglasan, 2014). A chitin binding protein called Drosocrystallin (Dcy) has been identified as part of the peritrophic matrix in the adult Drosophila midgut. Dcy-deficient flies have a reduced peritrophic matrix and are more sensitive to pathogens (Kuraishi et al., 2011).

As a result of Gram-negative bacteria and Gram-positive bacilli infection in the gut, an antibacterial pathway is activated and AMPs produced (Tzou et al., 2000, Ryu et al., 2006, Buchon et al., 2009). Flies with deficiencies in this pathway are more sensitive to oral infections with bacteria (Liehl et al., 2006, Nehme et al., 2007). 
The gut defense also comprises the production of reactive oxygen species (ROS) (Ha et al., 2005, Ryu et al., 2006). ROS are produced by the NADPH oxidase Duox. ROS act eliminating bacteria by damaging DNA, RNA and proteins and also by producing the oxidative degradation of lipids in cell membranes (Vatansever et al., 2013). Duox-RNAi flies are more susceptible following infection with bacteria (Ha et al., 2005).

\section{Through the genital organ}

The genitalia are other organs potentially exposed to infectious organisms. Traumatic mating is widespread in the animal kingdom and copulation can involve the wounding of the mating partner (Lange et al., 2013). Drosophila females present wounds on their genitalia after copulation (Kamimura $\mathrm{Y}$, 2007). This has been postulated as a significant cause of infection in the wild (Miest and Bloch-Qazi, 2008, Zhong et al., 2013). Highlighting the importance of this route of infection, many AMP genes are constitutively expressed in male and female genitalia of Drosophila (Tzou et al., 2000).

\section{Drosophila: most common modes of infection}

Different modes of infection are used to study host-pathogens interactions in Drosophila (Figure 2). Fruit flies can be infected by actively delivering the infective agent (bacteria, fungi or virus) into the body cavity (abdomen or thorax) of the adult or the larva (Neyen et al., 2014). This is achieved by pricking the body cavity of the insect with a needle that has been immersed in the pathogen, or by microinjection of the pathogen directly into the body cavity, which might mimic the bite of the insect's parasites or a wound in the 
cuticle. For example, it was shown that mites serve as a vector to transmit bacteria from one Drosophila species to another (Jaenike et al., 2007), and wounds left by mites can become secondarily infected by bacteria in honey bees pupae (Kanbar and Engels, 2003). Alternatively, flies with the first pair of legs cut and removed can be exposed to medium contaminated with bacteria (Kari et al., 2013). This method mimics injuries that flies suffer in the natural habitat.

\section{[insert Figure 2 here]}

Figure 2. Modes of infection used in Drosophila under laboratory conditions. Pathogens can be delivered by injection $(A)$ or pricking $(B)$ in the thorax or the abdomen. Alternatively, pathogens can be deposited over the cuticle $(C)$ or orally ingested (D). Other possible modes of infection include the deposition of pathogens in the male genital plaque $(E)$ or sexual transmission during mating $(\mathrm{F})$.

Although these approaches have been shown to be relevant for identifying pathogen virulence factors and host defense mechanisms, they bypass the entry of microbes through others routes of infection, such as the gut, trachea or genitalia. Additionally, the injury produced by the inoculation could trigger immune mechanisms independent of the infection (Chambers et al., 2014).

Drosophila are naturally exposed to pathogens while foraging on decaying fruit, with the most common route of access of pathogens being oral infection in the digestive system and/or contact with the tracheal system. Different experimental methods for oral infection in Drosophila have been described: exposing larvae with virus particles from the beginning of the first instar (Jousset and Plus, 1975, Lautie-Harivel, 1992, Gomariz-Zilber et al., 1998, 
Gomariz-Zilber et al., 1995, Gomariz-Zilber and Thomas-Orillard, 1993, Thomas-Orillard, 1988, Thomas-Orillard, 1984, Stevanovic and Johnson, 2015, Vale and Jardine, 2015), or by feeding adult flies with a mix of food and pathogen solution (Jousset and Plus, 1975, Gomariz-Zilber et al., 1995, Ferreira et al., 2014, Wong et al., 2016, Gupta et al., 2017a, Xu et al., 2013).

Topical infection is another method of infection in which the pathogen is put directly in contact with the host cuticle. This infection mode has been used with the entomopathogenic fungi Metarhizium anisopliae, that infects via direct penetration on the host cuticle during spore germination (Lu et al., 2015, Zhong et al., 2013).

The genital plate of Drosophila males is also a route of pathogen entry in males and deposition of bacteria on genitalia is sufficient to trigger both systemic and local expression of AMPs (Gendrin et al., 2009). Furthermore, sexual transmission of bacteria and fungi from male to female during mating was observed under laboratory conditions (Miest and Bloch-Qazi, 2008, Zhong et al., 2013).

Interestingly, Martins and coworkers (Martins et al., 2013) showed that host immune adaptation depends on the infection route taken by pathogens. They tested the evolution of resistance of Drosophila melanogaster against the Pseudomonas entomophila bacteria introduced through the cuticle (infection by pricking) or through the gut (upon oral infection). The host evolved resistance towards the bacteria for both routes of infection. However, adaptation to infection through one route does not protect from infection through the other. This route-specificity indicates that the physiological mechanisms of resistance and the evolutionary trajectories of adaptation differ 
for each route of infection. An example comes from a transcription profile analysis of Drosophila larvae infected with bacteria by oral infection compared to injection; the analysis showed that during oral infection genes related to the chitinous peritrophic matrix and genes involved in general metabolism are the most induced. These may reflect modifications that the gut cells undergo due to the presence of bacteria in the food (Vodovar et al., 2005).

\section{Infection outcomes and immune responses}

A systemic infection is an infection in which the pathogen is distributed throughout the body rather than concentrated in one area. In contrast, a local infection is an infection that has not spread but remains contained near the entry site (Taber, 2017).

It is commonly accepted that bacterial systemic infections take place in the body cavity of the insect and produce a systemic immune response that concerns AMP production, haemocytes and the release of AMPs from the fat body into the hemolymph. On the contrary, a local infection takes place in barrier epithelia such as the gut, the trachea or the reproductive tract. In this case, AMPs are expressed in the epithelia and produce a local immune response (Lemaitre and Hoffmann, 2007). In Drosophila, AMP expression is detected in most tissues that are in contact with the external environment with a higher chance of encountering a pathogen (Ferrandon et al., 1998, Tzou et al., 2000). The secretion of AMPs locally helps to prevent the spreading of infections and provides a first line of defense, which does not require the triggering of a systemic response. 
A septic injury in the body cavity of an insect is thought to start a systemic infection. However, it has been shown that oral infections with bacteria in Drosophila larvae (Vodovar et al., 2005, Basset et al., 2000) and adults (Nehme et al., 2007) are capable of also inducing systemic immune responses, even if bacteria only remain in the gut lumen (Liehl et al., 2006). These results indicate that an infection initiated at the epithelia could produce a systemic infection and trigger a systemic immune response. Similarly, in flies injected with Drosophila C virus (DCV), the virus is detected throughout the body. When flies are orally infected with DCV, the virus is found in other organs beyond the gut, even in haemocytes, showing a similar tropism to that of one after injection (Ferreira et al., 2014). Therefore, DCV is capable of generating a systemic infection independently of the infection mode.

Inducible responses such as the Janus kinase/signal transducer and activator of transcription (Jak/STAT), Toll and the Immune Deficiency (IMD) pathways (see the section Inducible responses below) also contribute to the antiviral host defense in Drosophila, although they involve virus-specific mechanisms (in contrast to RNAi, which is a general antiviral response) that remain poorly characterized. For this reason, the production and release of AMPs from the fat body into the hemolymph following a viral infection is not a good parameter to differentiate local from systemic viral immune responses. One measurable parameter that reveals a systemic viral response is the spread of antiviral signals from infection sites to distant uninfected tissues (Saleh et al., 2009). For example, it was suggested that viral small RNAs act as an antiviral signal during systemic spread of RNAi-based immunity (Tassetto et al., 2017). 
To simplify the interpretation of results in the bibliography, we distinguish the route of infection (through the cuticle, through the trachea, through the gut, through the genital organ), from the mode of infection (injection, pricking, topical infection, genitalia or trachea infection, sexual transmission, oral infection); and the infection outcome (systemic infection vs local infection) from the immune response triggered (systemic vs local immune response).

\section{Drosophila antiviral immune responses upon different routes and modes of infection}

Several natural viral pathogens have been described and used to investigate the genetic basis of antiviral resistance in Drosophila. The list includes the natural RNA viruses of Drosophila: DCV (Jousset and Plus, 1975), Nora virus (Habayeb et al., 2006), Drosophila A virus (DAV) (Brun, 1980), Drosophila X virus (DXV) (Teninges et al., 1979), Cricket Paralysis virus (CrPV) (Johnson and Christian, 1996) and Sigma virus (Teissier, 1937, Berkaloff et al., 1965). Also, non-natural viruses of Drosophila have been actively used as infection models: the RNA viruses Flock House virus (FHV), Sindbis virus (SINV), Vesicular stomatitis virus (VSV), and the DNA virus Invertebrate Iridescent virus 6 (IIV6).

As mentioned above, the infection route plays an important role in the fate of the infection and the fate of the host. For instance, a DNA microarray analysis of flies injected with DCV revealed that 140 genes were induced after infection. Most AMP genes were not upregulated or were only weakly upregulated by the infection (Dostert et al., 2005). However, the genes vir-1 (virus-induced RNA 1) and Vago (Dostert et al., 2005, Deddouche et al., 
2008) that are host factors involved in DCV replication, were upregulated. In another study the gene expression analysis was carried out in response to an oral infection with DCV (Roxstrom-Lindquist et al., 2004). Interestingly, only 80 genes showed upregulation in response to infection and some of these were the genes for the AMPs Attacin A, Cecropin A1, Cecropin A2, Drosomycin and Metchnikowin. Intriguingly, the genes vir-1 and Vago were not upregulated. Even if the dramatic differences on gene expression reported in both studies could be due to the different routes of virus infection, one cannot exclude that changes might be due to differences in the experiment design and data analysis. Of note, a genome-wide transcriptome study by next-generation sequencing of DCV-injected wild-type flies reveled that just 31 genes were regulated by the infection (Merkling et al., 2015b). The number and the identity of the upregulated genes are very different than those in the DNA microarray analysis discussed above (Dostert et al., 2005).

With the current availability of next generation sequencing techniques, it would be useful to perform gene expression studies in which flies of the same age, sex, genetic background, and reared in the same conditions are infected with different doses of DCV by injection or by oral infection. Only this kind of systematic and standardized comparative studies will shed light on the molecular mechanism underlying the effect of the route and mode of infection on the host immune response.

Below we will briefly describe the main responses involved in antiviral immunity in Drosophila and their differential regulation/expression depending on the infection route (Table 1). For more details in the different antiviral responses, see (Mussabekova et al., 2017, Merkling and van Rij, 2013). 


\section{[insert Table 1 here]}

Table 1. Antiviral responses and modes of infection in Drosophila.

\section{1-RNA interference}

When challenged with any virus, the most robust insect response is the RNAi pathway. The most compelling results demonstrating the antiviral role of RNAi come, once again, from Drosophila: i- flies with loss-of-function mutations for the three key genes of the small interfering RNA (siRNA) pathway, Dicer-2 (Dcr-2), Argonaute 2 (Ago-2), and r2d2, show increased sensitivity to infection by RNA and DNA viruses (Galiana-Arnoux et al., 2006, van Rij et al., 2006, Wang et al., 2006, Zambon et al., 2006); ii- Dicer-2-dependent 21-nucleotide siRNAs of viral origin accumulate in virus-infected flies (Galiana-Arnoux et al., 2006, Wang et al., 2006); iii- several insect viruses express viral suppressors of RNAi (Li et al., 2002, van Rij et al., 2006, Nayak et al., 2010).

The importance of the RNAi pathway in the control of viral infections has been confirmed in other insects, in particular, the disease vector mosquito genera Aedes and Culex, which transmit important human pathogens such as dengue virus, West Nile virus, and other arthropod-borne viruses (SanchezVargas et al., 2009, Brackney et al., 2009).

Although, the RNAi pathway has been proposed as the most important antiviral mechanism in insects, all the studies conducted in Drosophila were performed by injecting lethal doses of virus directly to the adult fly haemocel and producing viral systemic infections (Galiana-Arnoux et al., 2006, van Rij et al., 2006, Wang et al., 2006, Zambon et al., 2006). The antiviral role of 
RNAi during oral infections (mimicking natural infections by feeding) remains to be confirmed.

\section{2-Inducible responses}

Another component of the antiviral innate immune system are signal transduction pathways resulting in changes in cellular gene expression, such as the NF-KB pathways (Toll and IMD), which play essential roles in antibacterial and antifungal responses, and the cytokine-activated Jak-STAT pathway. Common downstream processes of these pathways include the production of humoral factors, such as AMPs secreted from the fat body, and phagocytosis, encapsulation and melanization of the hemolymph (Lemaitre and Hoffmann, 2007). As already mentioned, their role during the antiviral response is secondary and involves virus-specific responses, which remain poorly characterized.

Below are some examples:

* Jak/STAT pathway: it was shown in Drosophila that injections with DCV and CrPV induce the expression of Jak-STAT dependent genes (Kemp et al., 2013, Dostert et al., 2005, Merkling et al., 2015a). Global transcription profiles of flies injected with DCV showed induction of vir-1 dependent on Hopscotch, the sole Jak kinase of Drosophila. Deficient mutant flies in hopscotch, showed increased viral load and sensitivity to DCV and CrPV injection (Kemp et al., 2013, Dostert et al., 2005). Thus, flies respond to DCV and CrPV injection by inducing a transcriptional response mediated in part by the Jak-STAT pathway. However, the overexpression of vir-1 or the knockdown of vir-1 in flies, did not affect resistance to DCV infection. This suggests that vir-1 does 
not have a direct role in the immune control of DCV infection (Dostert et al., 2005).

In another study, reduced expression of STAT resulted in increased production of SINV replicon, suggesting that the Jak-STAT pathway is involved in controlling SINV replication (Avadhanula et al., 2009). Of note, SINV replicon refers to a transgenic fly line that produces non-structural SINV proteins and is capable of autonomous replication. In addition, several transcripts with STAT binding sites are regulated by SINV infection, among them the AMP attacin $C(A t t C)$. The knockdown of AttC in flies resulted in an increase in virus titers after injection with SINV (Huang et al., 2013).

Interesting, the histone methyltransferase G9a contributes to tolerance after viral infection by regulating the Jak-STAT pathway. In deficient mutant flies for G9a, the hyperactivation of the Jak-STAT pathway has been associated with an increase in lethality in DCV-Injected flies (Merkling et al., 2015a).

It is important to note that the involvement of Jak-STAT pathway in the antiviral response in Drosophila has only been tested upon injection of viruses or replicon systems.

* IMD pathway: different studies show that the IMD pathway is involved in antiviral immunity. Most of these studies were performed using viral replicons and viral injections. One study showed that intrathoracic injections of SINV into loss-of-function relish mutant flies produced higher viral loads and enhanced viral replication compared to wild type flies. An induction of AMPs Diptericin and Metchnikowin also was detected using SINV replicon in flies (Avadhanula et al., 2009). Moreover, it was found that Diptericin B (DptB) was upregulated by the infection and flies with knockdown of DptB showed an 
increase in virus titers (Huang et al., 2013). More recently it was shown that a protein encoded by the virus-induced Drosophila gene diedel (die) is induced after viral injection and also promotes host survival by modulating the activation of the IMD pathway and NF-KB signaling (Lamiable et al., 2016b).

In others experiments CrPV was injected into mutants of the IMD pathway resulting in increased sensitivity to CrPV infection and higher viral load. The infection in wild type flies did not induce AMP production, but haemocytes were depleted during the course of the infection (Costa et al., 2009). These results suggest that activation of the IMD pathway can be uncoupled from the induction of AMP genes and depends on cellular rather than humoral mechanisms during viral infections.

A recent study used oral infection of mutant flies for key players of the IMD pathway (Tak1, Relish, Imd). These flies displayed an increase in viral replication specifically in the intestine upon DCV or SINV oral challenge. Moreover, it was demonstrated that the microbiota in the fly gut activates the IMD signaling and boosts the antiviral defense (Sansone et al., 2015). See the Virus-bacteria interactions section below for more information.

* Toll pathway: this pathway has been associated with resistance to the dsRNA DXV virus. Infection with DXV leads to a strong induction of AMPs and a loss-of-function mutant in Dif was more susceptible to viral challenge and allowed increased viral replication, but the role of the Toll pathway in resistance to DXV is not clear since other loss-of-function mutants from the pathway (pelle, Toll, spätzle and tube) were not found to be more susceptible to DXV infection. Constitutive activation of the pathway, in a Toll gain-offunction mutant, also leads to higher susceptibility to DXV but decrease in 
viral titer. This suggests that the constitutive activation of the Toll pathway is able to retard viral replication but not to affect the global result of the infection. It was proposed that DXV titer may be partially independent of the pathogenic effects of infection (Zambon et al., 2005) and that Dif regulates antiviral activity by a non-classical mechanism (Mussabekova et al., 2017). Moreover, a direct antiviral activity of the induced AMPs could not be established since enhanced expression of single AMPs did not alter resistance to viral infection or viral titers (Zambon et al., 2005).

In recent work, the role of the Toll pathway in several RNA virus infections (DCV, CrPV, FHV and Nora virus) was analyzed by comparing two different infections routes: through the gut (oral infection) vs. the cuticle (pricking in the thorax). It was shown that several Toll pathway components are required to resist virus oral infections but not infection by pricking. The results showed that NF-kB-like transcription factors Dorsal, but not Dif, is required for viral resistance. Interestingly, DCV induced the translocation of Dorsal from the cytoplasm to the nucleus in fat body cells after both types of infections (oral and pricking). This indicates that the pathway is activated no matter the infection mode, but is only effective during an oral infection (Ferreira et al., 2014). These results confirm that the interaction of viruses with Drosophila change with the route of infection and that the antiviral action of the Toll pathway targets a step of the viral cycle specific to the infection route.

\section{2- $\underline{\text { Cellular responses }}$}

Phagocytosis, apoptosis and autophagy are cellular processes that limit viral replication and dissemination in insects. Their involvement in antiviral 
response in Drosophila also has been investigated only in infections by injection.

* Phagocytosis: it is a fundamental process in the immune response of animals and it allows for rapid engulfment of pathogens and apoptotic cells. It was observed that phagocytosis-inhibited flies succumbed to CrPV injection faster than controls flies indicating that phagocytosis is an important antiviral mechanism (Costa et al., 2009). In addition, by injecting a panel of different viruses in flies genetically depleted for haemocytes (blood cells), a decrease in survival upon intrathoracic injection with CrPV, FHV and VSV, but not DCV, SINV or IIV6 was observed (Lamiable et al., 2016a).

* Apoptosis: the process of programmed cell death is considered a component of differential cellular processes just as cell turnover, proper development, and functioning of the immune system including the restriction of viral replication. Apoptosis limits the time and the cellular machinery available for the virus, decreasing viral dissemination in the viral host (Roulston et al., 1999). Evading or delaying apoptosis is an important mechanism for some viruses to establish infection. On the other hand, viruses may stimulate apoptosis at later stages of infection to induce the breakdown of infected cells to favor viral dissemination.

Studies in Drosophila flies injected with FHV showed induction of reaper, a proapoptotic gene, in a p53-dependent manner, indicating that apoptosis is capable of limiting viral replication. Moreover, p53 deficient mutant flies showed increased levels of FHV RNA and viral titers (Liu et al., 2013). In addition, a mechanism of apoptosis-dependent phagocytosis that removes virus-infected cells was induced in DCV injected flies (Nainu et al., 2015). 
* Autophagy: it is a process by which cells degrade cytoplasmic components, including organelles, through the lysosomal degradation pathway. Several studies have implicated autophagy in restricting the replication and elimination of pathogens, including bacteria, protozoa and viruses (Levine et al., 2009). It has been demonstrated that autophagy plays an important antiviral role against VSV and Rift Valley Fever virus (RVFV) in adult flies. Transgenic flies depleted for different autophagy genes and injected with VSV or RVFV, became more sensitive to the virus and exhibited increased viral titers (Shelly et al., 2009, Lamiable et al., 2016a, Moy et al., 2014). SINV, DCV, CrPV, or IIV6 injected in Atg7 (protein involved in autophagosome biogenesis) deficient mutant flies did not show any difference in survival, suggesting that autophagy is not an important mechanism for the replication of these viruses (Lamiable et al., 2016a).

Of note, it was proposed that the Toll-7 receptor activates induced antiviral autophagy and restricts viral replication against VSV and RVFV in flies (Nakamoto et al., 2012, Moy et al., 2014). However, another study claims that Toll-7 does not participate in the autophagy against VSV (Lamiable et al., 2016a). All these results indicate that cellular antiviral responses in Drosophila involve virus-specific mechanisms, which needs to be studied more thoroughly and should be verified using different infection routes.

\section{Others factors involved in antiviral immunity}

Other host factors have been identified as limiting or restricting viral replication in Drosophila. 
* Vago: was identified as an upregulated RNA by microarray analysis of DCVinjected flies (Dostert et al., 2005). DCV replication is increased in the fat body of Vago loss-of-function mutant. However, these flies did not succumb to DCV infection more rapidly than wild-type flies. The DExD/H-box helicase domain of Dicer-2 was required for Vago induction, suggesting that in addition to its involvement in RNAi, Dicer-2 sense dsRNA and triggers an inducible antiviral response (Deddouche et al., 2008).

* dFOXO: the Drosophila forkhead box O (FOXO) transcription factor binds to the promoters of Ago-2 and Dcr-2 activating their transcription. dFOXO null mutant flies are more sensitive to CrPV and FHV infection. This phenotype can be rescued by overexpressing Dcr-2, suggesting that the effect of $d F O X O$ on viral immunity is likely due to RNAi expression defects. (Spellberg and Marr, 2015).

* Heat-shock pathway: analysis of global transcription upon DCV or CrPV injection in flies, reveled a strong induction of the heat shock RNAs. Moreover, mutant flies deficient for the heat shock response were hypersensitive to the infection, and overexpression of the heat shock proteins induces resistance to infection. These results suggest that the heat shock response is important for the antiviral response (Merkling et al., 2015b).

* Polymorphisms and virus sensitivity: pastrel (Magwire et al., 2012, Martins et al., 2014) and Ubc-E2H (Martins et al., 2014) are genes that are found as a cluster of polymorphisms that have been associated with resistance or susceptibility to DCV or CrPV viral injections respectively. Importantly, the knockdown of pastrel or Ubc-E2H led to a reduced survival upon challenge with DCV or CrPV, but not FHV. 
It remains to be demonstrated if $\mathrm{Vago,} d F O X O$, the heat shock pathway and the described polymorphisms are involved in the antiviral response after an oral challenge.

\section{Virus-bacteria interactions}

Drosophila is associated with a microbiome that makes essential contributions to the host health and physiology, including nutrition, metabolic homeostasis, and mating preference (Mistry et al., 2016, Sharon et al., 2010). The midgut microbiota influence nutrition, development, behavior, and pathogen resistance (Buchon et al., 2013). The resident gut bacteria activate the IMD signaling in intestinal epithelial cells, but the pathway is negatively regulated to maintain the equilibrium and to prevent microbiota clearance from the gut (Ryu et al., 2008). Antibiotic treated flies (axenic flies, without microbiota), showed higher viral replication levels in the intestine after an oral challenge with DCV or VSV (Sansone et al., 2015). These results suggest that the microbiota is required for the antiviral defense in the gut. Intriguingly, when the survival of DCV orally infected axenic flies was analyzed by Ferreira and coworkers, there was no difference when compared with non-axenic infected flies (Ferreira et al., 2014). This result suggest that microbiota could be important in controlling the local infection at the gut level, but other antiviral mechanisms could be relevant in determine the outcome of the infection.

Recently it was shown that the nutrient responsive Extracellular signalRegulated Kinase (ERK) pathway is a regulator of intestinal immunity against different viruses. Using ERK pathway inhibitors and driving the reduction of ERK in the gut by genetic knockouts, it was found that this pathway restricts 
VSV, SINV and DCV infection in the gut epithelia of orally infected adult flies (Xu et al., 2013). Moreover, the ligand Pvf2 is induced during a viral infection and activates the receptor tyrosine kinase (PVR), which activates the ERK pathway in enterocytes. Additionally, the induction of Pvf2 is also induced by the gut microbiota signaling through the NF-kB-IMD pathway, which primes the antiviral response (Sansone et al., 2015). Interestingly these findings provide a link between the gut as an active barrier against infection, the microbiota and the antiviral responses in the host.

Wolbachia pipientis are maternally transmitted, obligatory intracellular bacteria that infect a great number of species of arthropods and nematodes (Werren et al., 2008). Wolbachia mediates protection in adult flies following DCV, CrPV, FHV or Nora virus injection (Hedges et al., 2008, Teixeira et al., 2008). Interesting, the same Drosophila-Wolbachia associations have a protective effect against DCV following oral infection in adults (Ferreira et al., 2014, Stevanovic et al., 2015). The density of Wolbachia in adults and larvae orally infected and adults infected by injection correlate with protection against DCV (Stevanovic et al., 2015, Osborne et al., 2012); however, changing gut microbiota composition does not seem to be the way by which Wolbachia conveys antiviral protection to its host (Ye et al., 2017). Recently, new evidence indicates that Wolbachia acts by increasing the expression of the Drosophila methyltransferase gene Mt2 to confer resistance to a SINV infection by injection (Bhattacharya et al., 2017). 


\section{The most studied Drosophila virus: DCV}

DCV is the most studied Drosophila natural pathogen, a positive sense RNA virus that belongs to the Dicistroviridae family. Even though it is a widespread pathogenic enterovirus, most studies involving DCV have been performed by viral injections; while oral infection, probably the most frequent route of infection, has largely been unexplored. In general, DCV injected into flies causes complete mortality within three to 13 days post infection, depending on the viral dose and the genetic background (Jousset et al., 1972, GalianaArnoux et al., 2006, van Rij et al., 2006, Dostert et al., 2005, Merkling et al., 2015a). It is also possible to generate sub-lethal infections by injecting with low viral doses (Longdon et al., 2013, Gupta et al., 2017a, Ferreira et al., 2014). DCV injected flies have a reduction in metabolic rate, an increase of fresh mass (Arnold et al., 2013) and a depression in locomotor activity (Arnold et al., 2013, Gupta et al., 2017a). Also, DCV sub-lethal injections were showed to increase fly fecundity (Gupta et al., 2017a).

From a cellular aspect, the clathrin-mediated endocytosis pathway is essential for infection and pathogenesis of DCV (Cherry and Perrimon, 2004). Interestingly, midgut specific genes are strongly repressed by infection. This repression is associated with nutritional stress and an intestinal obstruction produced by a malfunctioning of the crop, a food storage organ (Chtarbanova et al., 2014). It would be interesting to determine if the midgut gene repression and the pathology affecting the crop are also observed upon an oral infection. In different studies, when DCV was orally delivered in Drosophila larvae, a pre-adult mortality was observed (Jousset and Plus, 1975, Gomariz-Zilber and Thomas-Orillard, 1993, Thomas-Orillard, 1988, Stevanovic and Johnson, 
2015). Despite this increased death rate, a selective advantage in the emerging DCV-infected adult flies was observed: i- shorter development time, ii- an increase in the number of ovarioles and in the fresh weight (ThomasOrillard, 1984, Gomariz-Zilber and Thomas-Orillard, 1993), iii- an increase in the egg-production (Thomas-Orillard, 1990), iv- an increase in fertility (Thomas-Orillard, 1988). This selective advantage could be due to a positive direct effect of DCV during the adult stage, but it could also be due to an indirect effect of the selection process produced by the infection. Maybe weaker larvae with lower fitness succumb to the infection, and the remaining population with the described advantages is selected.

When adult flies were orally infected with DCV, the infection was sublethal (Gupta et al., 2017a), or lethal in just some flies (Jousset and Plus, 1975, Ferreira et al., 2014, Wong et al., 2016). In orally infected adult flies the benefits of DCV infections in fecundity were shown in only two of ten genetic backgrounds tested and the locomotor activity was not affected (Gupta et al., 2017a). However, in an ealier study in which flies were exposed to a higher viral concentration, female flies showed reduced locomotor activity (Vale and Jardine, 2015). The oral infection of adults was also associated with a general reduction in fecal excretion (Gupta et al., 2017a), in concordance with the phenotype of intestinal obstruction observed in DCV injected flies (Chtarbanova et al., 2014).

\section{DCV tropism and the infection mode}

One of the most marked differences between a DCV infection initiated by injection or by an oral infection in flies is related to the fate of the infection. 
After a DCV injection, in most cases, all flies die. Nevertheless, in flies orally infected or coming from infected larvae, a mortality ranging from 10 to $25 \%$, was observed, even when highly concentrated viral stock was used (Wong et al., 2016, Ferreira et al., 2014). This suggests once again that the viral tropism, the immune response and the pathology associated with the infection could vary depending on the infection mode.

Several studies addressed the localization of DCV in tissues after injection in adult flies. The target organs were muscles surrounding the gut and trachea, tracheal cells, follicular cells and Malpighi tubes (Jousset et al., 1972, LautieHarivel and Thomas-Orillard, 1990, Lautie-Harivel, 1992, Cherry and Perrimon, 2004, Ferreira et al., 2014). A more detailed analysis of the digestive tract showed that DCV can also be detected in the muscles surrounding the crop. Interesting, this specific tropism was associated with a failed crop function, which ultimately induced starvation in infected flies (Chtarbanova et al., 2014). This result support previous observations showing that DCV infection produces an increase in fresh mass and a decreased metabolic rate (Arnold et al., 2013).

In a comparative analysis of flies upon virus delivery by injection or by oral infection it was found that, independent of the delivery route, DCV tropism remains the same (Ferreira et al, 2014). The virus was detected by immunofluorescence in the fat body, visceral muscles of the gut, gonads and haemocytes. However, a closer look to these results revealed that only two out of 20 orally infected flies show this widespread virus distribution, with most of the infected flies showing virus at low intensity only in the gut and the fat body. Intriguingly, all orally infected flies showed viral presence when 
measuring DCV RNA levels of single flies by qRT-PCR. It is however remarkable, that the relative DCV levels at 20 days post infection are lower than at five days (Ferreira et al, 2014). It was also observed that flies from nature lose the virus through several passages in laboratory conditions after being collected in the field (Jousset and Plus, 1975, Thomas-Orillard, 1984). These observations suggested that a mechanism of control of the infection is involved, and that a viral clearance mechanism of DCV, so far unreported, could exist.

In another study DCV was detected in the intestinal visceral muscles in only $4 \%$ of the orally infected flies (Xu et al., 2013). This observation suggests that in most oral infections of DCV, the virus could localize and be controlled locally at the gut level. In some cases, the virus would be capable of breaching the midgut barrier, infecting the visceral muscles, reaching the haemolymph, spreading systemically and eventually killing the fly. However, this hypothesis should be tested by performing a more exhaustive immunestaining analysis or by directly searching for the presence of DCV in fly haemolymph after an oral infection.

So far, only one study (Lautie-Harivel, 1992) analyzed the DCV tropism in Drosophila larvae infected orally and in the adults derived from these larvae. First instar larvae were exposed to DCV until the beginning of the third instar when they were collected and immunostained for DCV localization. The virus was principally detected in larvae that seemed unhealthy (those that move more slowly) in the lumen of the digestive tract and in the basal part of gut cells. Once again, two different scenarios could explain this observation: iDCV immunostaining is not sensitive enough to detect the virus when 
replication is weak, ii- not all larvae became infected. In support of the first scenario, the viral infection was confirmed by a biological test, which consists of injecting a filtered crushing of the supposedly contaminated larvae into noninfected flies and scoring mortality. However, one can speculate that even if larvae were treated to eliminate the virus that was fixed on the exterior cuticle, the input virus could remain in the gut and does not reflect viral replication. Indeed, a study showed that DCV viral replication was only detected in only 10 to $20 \%$ of larvae exposed to DCV (Stevanovic and Johnson, 2015). These differences in virus replication between larvae could explain the largely reported partial pre-adult mortality mentioned above.

Regarding the tissue tropism in adult flies derived from infected larvae, unexpectedly DCV was not detected by immunostaining in any of the tissues analyzed, even if the virus was detected by a biological test (Lautie-Harivel, 1992). Other study showed that in the emerging adults there was no virus actively replicating (Stevanovic and Johnson, 2015). These results suggest that adult flies coming from larvae infected with DCV are carrying the virus, but that the virus is not actively replicating. This observation negates a direct effect of viral replication in the adult stage on the selective advantage observed in the emerging DCV-infected adult flies (discussed above). Nevertheless, data produced in our own laboratory shows that adult flies from infected larvae display a $15 \%$ mortality, and that the virus is actively replicating in adult emerged flies (Mondotte et. al., unpublished). These results highlight that variables such as the DCV and fly strain used, viral concentration, time of infection, etc., are important to consider and could 
change the fate of the infection and the interpretation of the biological process.

\section{Conclusions and future perspectives}

The use of Drosophila as a model organism has made an important contribution to our understanding of the function and regulation of innate immunity in insects. Indeed, insects can discriminate between different types of pathogens and mount specific and effective responses. Strikingly, the same pathogen can trigger a different immune response in the same organism, depending solely on the route of infection by which the pathogen is delivered. Different modes of infection have been used to study virus-host pathogens. Direct injection of the virus provides an efficient and reproducible mode of infection that has been widely used to understand the antiviral response of the host, to determine host factors involved in the control of the infection, and to identify suppressors encoded by viruses to avoid the antiviral response. Nevertheless, special attention should be paid to oral infections that are probably the most common route of infection during the natural insect life cycle. During an oral infection, viruses face specific antiviral pathways in the gut and trigger different immune responses compared to direct injection, and are probably subject to more layers of control. However, there are several limitations to the use of oral infections as a standard procedure in the laboratory, and the control of viral input and the developmental stage of the insect at the moment of infection represent a major challenge for this approach. 
Analysis of immunity in the gut deserves special attention in light of its importance to restrict dissemination of viruses and the complexity imposed by the microbiota. Due to the current outbreaks of emerging and remerging mosquito borne viral diseases, mosquitoes are being used more frequently as a model insect in laboratories. As the possibility of using genetically modified mosquitos become more accessible, it becomes of crucial importance to confirm findings of antiviral immunity discovered in Drosophila in mosquito using similar infection routes.

To conclude, one key message from this review is that, the literature concerning the insect antiviral response is sparse, fragmentary and sometimes inconsistent. The use of different insect and virus models, inoculation routes, and different experimental conditions make it difficult to compare results on the mechanisms involved in response to virus infection. Systematic and standardized approaches are needed before any conclusions can be drawn on the antiviral activity of immune pathways in insects.

\section{Acknowledgements}

We apologize to all of our colleagues whose work has not been cited due to space constraints. We thank Vanesa Mongelli and Elizabeth Jaworski for fruitful discussions and help with editing. Chloé Baron for art work. This work was supported by the European Research Council (FP7/2013-2019 ERC CoG 615220) and the French Government's Investissement d'Avenir program, Laboratoire d'Excellence Integrative Biology of Emerging Infectious Diseases (grant ANR-10-LABX-62-IBEID) to MCS. JAM was supported by AXA Research fund. 


\section{REFERENCES}

ARNOLD, P. A., JOHNSON, K. N. \& WHITE, C. R. 2013. Physiological and metabolic consequences of viral infection in Drosophila melanogaster. $J$ Exp Biol, 216, 3350-7.

AVADHANULA, V., WEASNER, B. P., HARDY, G. G., KUMAR, J. P. \& HARDY, R. W. 2009. A novel system for the launch of alphavirus RNA synthesis reveals a role for the Imd pathway in arthropod antiviral response. PLoS Pathog, 5, e1000582.

BASSET, A., KHUSH, R. S., BRAUN, A., GARDAN, L., BOCCARD, F., HOFFMANN, J. A. \& LEMAITRE, B. 2000. The phytopathogenic bacteria Erwinia carotovora infects Drosophila and activates an immune response. Proc Natl Acad Sci U S A, 97, 3376-81.

BAXTER, R. H., CONTET, A. \& KRUEGER, K. 2017. Arthropod Innate Immune Systems and Vector-Borne Diseases. Biochemistry, 56, 907918.

BEHRENS, S., PEUSS, R., MILUTINOVIC, B., EGGERT, H., ESSER, D., ROSENSTIEL, P., SCHULENBURG, H., BORNBERG-BAUER, E. \& KURTZ, J. 2014. Infection routes matter in population-specific responses of the red flour beetle to the entomopathogen Bacillus thuringiensis. BMC Genomics, 15, 445.

BERGMAN, P., SEYEDOLESLAMI ESFAHANI, S. \& ENGSTROM, Y. 2017. Drosophila as a Model for Human Diseases-Focus on Innate Immunity in Barrier Epithelia. Curr Top Dev Biol, 121, 29-81.

BERKALOFF, A., BREGLIANO, J. C. \& OHANESSIAN, A. 1965. [Demonstration of virions in Drosophila infected by the hereditary sigma virus]. C R Acad Sci Hebd Seances Acad Sci D, 260, 5956-9.

BHATTACHARYA, T., NEWTON, I. L. G. \& HARDY, R. W. 2017. Wolbachia elevates host methyltransferase expression to block an RNA virus early during infection. PLoS Pathog, 13, e1006427.

BRACKNEY, D. E., BEANE, J. E. \& EBEL, G. D. 2009. RNAi targeting of West Nile virus in mosquito midguts promotes virus diversification. PLoS Pathog, 5, e1000502.

BREY, P. T., LEE, W. J., YAMAKAWA, M., KOIZUMI, Y., PERROT, S., FRANCOIS, M. \& ASHIDA, M. 1993. Role of the integument in insect immunity: epicuticular abrasion and induction of cecropin synthesis in cuticular epithelial cells. Proc Natl Acad Sci U S A, 90, 6275-9.

BRUN, G. P. N. 1980. The viruses of Drosophila. In The Genetics and Biology of Drosophila, New York: Academic Press. 
BUCHON, N., BRODERICK, N. A. \& LEMAITRE, B. 2013. Gut homeostasis in a microbial world: insights from Drosophila melanogaster. Nat Rev Microbiol, 11, 615-26.

BUCHON, N., BRODERICK, N. A., POIDEVIN, M., PRADERVAND, S. \& LEMAITRE, B. 2009. Drosophila intestinal response to bacterial infection: activation of host defense and stem cell proliferation. Cell Host Microbe, 5, 200-11.

CHAMBERS, M. C., JACOBSON, E., KHALIL, S. \& LAZZARO, B. P. 2014. Thorax injury lowers resistance to infection in Drosophila melanogaster. Infect Immun, 82, 4380-9.

CHERRY, S. \& PERRIMON, N. 2004. Entry is a rate-limiting step for viral infection in a Drosophila melanogaster model of pathogenesis. Nat Immunol, 5, 81-7.

CHTARBANOVA, S., LAMIABLE, O., LEE, K. Z., GALIANA, D., TROXLER, L., MEIGNIN, C., HETRU, C., HOFFMANN, J. A., DAEFFLER, L. \& IMLER, J. L. 2014. Drosophila C virus systemic infection leads to intestinal obstruction. J Virol, 88, 14057-69.

COSTA, A., JAN, E., SARNOW, P. \& SCHNEIDER, D. 2009. The Imd pathway is involved in antiviral immune responses in Drosophila. PLOS One, 4, e7436.

DAVIS, M. M. \& ENGSTROM, Y. 2012. Immune response in the barrier epithelia: lessons from the fruit fly Drosophila melanogaster. $J$ Innate Immun, 4, 273-83.

DEDDOUCHE, S., MATT, N., BUDD, A., MUELLER, S., KEMP, C., GALIANA-ARNOUX, D., DOSTERT, C., ANTONIEWSKI, C., HOFFMANN, J. A. \& IMLER, J. L. 2008. The DExD/H-box helicase Dicer-2 mediates the induction of antiviral activity in drosophila. Nat Immunol, 9, 1425-32.

DOSTERT, C., JOUANGUY, E., IRVING, P., TROXLER, L., GALIANAARNOUX, D., HETRU, C., HOFFMANN, J. A. \& IMLER, J. L. 2005. The Jak-STAT signaling pathway is required but not sufficient for the antiviral response of drosophila. Nat Immunol, 6, 946-53.

ENGELHARD, E. K., KAM-MORGAN, L. N., WASHBURN, J. O. \& VOLKMAN, L. E. 1994. The insect tracheal system: a conduit for the systemic spread of Autographa californica $M$ nuclear polyhedrosis virus. Proc Natl Acad Sci U S A, 91, 3224-7.

FERRANDON, D., JUNG, A. C., CRIQUI, M., LEMAITRE, B., UTTENWEILER-JOSEPH, S., MICHAUT, L., REICHHART, J. \& HOFFMANN, J. A. 1998. A drosomycin-GFP reporter transgene reveals a local immune response in Drosophila that is not dependent on the Toll pathway. EMBO J, 17, 1217-27.

FERREIRA, A. G., NAYLOR, H., ESTEVES, S. S., PAIS, I. S., MARTINS, N. E. \& TEIXEIRA, L. 2014. The Toll-dorsal pathway is required for resistance to viral oral infection in Drosophila. PLoS Pathog, 10, e1004507.

FOOTTIT, R. \& ADLER, P. H. 2009. Insect biodiversity : science and society, Chichester, UK ; Hoboken, NJ, Wiley-Blackwell.

GALIANA-ARNOUX, D., DOSTERT, C., SCHNEEMANN, A., HOFFMANN, J. A. \& IMLER, J. L. 2006. Essential function in vivo for Dicer-2 in host defense against RNA viruses in drosophila. Nat Immunol, 7, 590-7. 
GANESAN, S., AGGARWAL, K., PAQUETTE, N. \& SILVERMAN, N. 2011. NF-kappaB/Rel proteins and the humoral immune responses of Drosophila melanogaster. Curr Top Microbiol Immunol, 349, 25-60.

GENDRIN, M., WELCHMAN, D. P., POIDEVIN, M., HERVE, M. \& LEMAITRE, B. 2009. Long-range activation of systemic immunity through peptidoglycan diffusion in Drosophila. PLoS Pathog, 5, e1000694.

GHABRIAL, A., LUSCHNIG, S., METZSTEIN, M. M. \& KRASNOW, M. A. 2003. Branching morphogenesis of the Drosophila tracheal system. Annu Rev Cell Dev Biol, 19, 623-47.

GOMARIZ-ZILBER, E., JEUNE, B. \& THOMAS-ORILLARD, M. 1998. Limiting conditions of the horizontal transmission of the Drosophila $\mathrm{C}$ virus in its host (D-melanogaster). Acta Oecologica-International Journal of Ecology, 19, 125-137.

GOMARIZ-ZILBER, E., PORAS, M. \& THOMAS-ORILLARD, M. 1995. Drosophila C virus: experimental study of infectious yields and underlying pathology in Drosophila melanogaster laboratory populations. J Invertebr Pathol, 65, 243-7.

GOMARIZ-ZILBER, E. \& THOMAS-ORILLARD, M. 1993. Drosophila C virus and Drosophila hosts a good association in various environments, Journal of Evolutionary Biology Volume 6, Issue 5. Journal of Evolutionary Biology [Online], 6.

GULLAN, P. J. \& CRANSTON, P. S. 2010. The insects : an outline of entomology, Chichester, West Sussex, UK ; Hoboken, NJ, WileyBlackwel.

GUPTA, V., STEWART, C. O., RUND, S. S. C., MONTEITH, K. \& VALE, P. F. 2017a. Costs and benefits of sublethal Drosophila $C$ virus infection. $J$ Evol Biol.

GUPTA, V., VASANTHAKRISHNAN, R. B., SIVA-JOTHY, J., MONTEITH, K. M., BROWN, S. P. \& VALE, P. F. 2017b. The route of infection determines Wolbachia antibacterial protection in Drosophila. Proc Biol Sci, 284.

HA, E. M., OH, C. T., BAE, Y. S. \& LEE, W. J. 2005. A direct role for dual oxidase in Drosophila gut immunity. Science, 310, 847-50.

HABAYEB, M. S., EKENGREN, S. K. \& HULTMARK, D. 2006. Nora virus, a persistent virus in Drosophila, defines a new picorna-like virus family. $J$ Gen Virol, 87, 3045-51.

HEDGES, L. M., BROWNLIE, J. C., O'NEILL, S. L. \& JOHNSON, K. N. 2008. Wolbachia and virus protection in insects. Science, 322, 702.

HILL, D. S. 1997. The economic importance of insects, London

London ; New York, Institute of Biology ;

Chapman \& Hall.

HUANG, Z., KINGSOLVER, M. B., AVADHANULA, V. \& HARDY, R. W. 2013. An antiviral role for antimicrobial peptides during the arthropod response to alphavirus replication. $J$ Virol, 87, 4272-80.

JAENIKE, J., POLAK, M., FISKIN, A., HELOU, M. \& MINHAS, M. 2007. Interspecific transmission of endosymbiotic Spiroplasma by mites. Biol Lett, 3, 23-5.

JENNINGS, B. H. 2011. Drosophila - a versatile model in biology \& medicine. Materials Today, 14, 190-195. 
JOHNSON, K. N. \& CHRISTIAN, P. D. 1996. A molecular taxonomy for cricket paralysis virus including two new isolates from Australian populations of Drosophila (Diptera: Drosophilidae). Arch Virol, 141, 1509-22.

JOUSSET, F. X. \& PLUS, N. 1975. [Study of the vertical transmission and horizontal transmission of "Drosophila melanogaster" and "Drosophila immigrans" picornavirus (author's transl)]. Ann Microbiol (Paris), 126, 231-49.

JOUSSET, F. X., PLUS, N., CROIZIER, G. \& THOMAS, M. 1972. [Existence in Drosophila of 2 groups of picornavirus with different biological and serological properties]. C R Acad Sci Hebd Seances Acad Sci D, 275, 3043-6.

KANBAR, G. \& ENGELS, W. 2003. Ultrastructure and bacterial infection of wounds in honey bee (Apis mellifera) pupae punctured by Varroa mites. Parasitology Research, 90, 349-354.

KARI, B., ZSAMBOKI, J., HONTI, V., CSORDAS, G., MARKUS, R., ANDO, I. \& KURUCZ, E. 2013. A novel method for the identification of factors involved in host-pathogen interactions in Drosophila melanogaster. $J$ Immunol Methods, 398-399, 76-82.

KEMP, C., MUELLER, S., GOTO, A., BARBIER, V., PARO, S., BONNAY, F., DOSTERT, C., TROXLER, L., HETRU, C., MEIGNIN, C., PFEFFER, S., HOFFMANN, J. A. \& IMLER, J. L. 2013. Broad RNA interferencemediated antiviral immunity and virus-specific inducible responses in Drosophila. J Immunol, 190, 650-8.

KIRKPATRICK, B. A., WASHBURN, J. O., ENGELHARD, E. K. \& VOLKMAN, L. E. 1994. Primary infection of insect tracheae by Autographa californica M nuclear polyhedrosis virus. Virology, 203, 184-6.

KURAISHI, T., BINGGELI, O., OPOTA, O., BUCHON, N. \& LEMAITRE, B. 2011. Genetic evidence for a protective role of the peritrophic matrix against intestinal bacterial infection in Drosophila melanogaster. Proc Natl Acad Sci U S A, 108, 15966-71.

LAMIABLE, O., ARNOLD, J., DE FARIA, I. J., OLMO, R. P., BERGAMI, F., MEIGNIN, C., HOFFMANN, J. A., MARQUES, J. T. \& IMLER, J. L. 2016a. Analysis of the Contribution of Hemocytes and Autophagy to Drosophila Antiviral Immunity. J Virol, 90, 5415-26.

LAMiABle, O., KELlENBERGER, C., KEMP, C., TROXLER, L., PELTE, N., BOUTROS, M., MARQUES, J. T., DAEFFLER, L., HOFFMANN, J. A., ROUSSEL, A. \& IMLER, J. L. 2016b. Cytokine Diedel and a viral homologue suppress the IMD pathway in Drosophila. Proc Natl Acad Sci U S A, 113, 698-703.

LANGE, R., REINHARDT, K., MICHIELS, N. K. \& ANTHES, N. 2013. Functions, diversity, and evolution of traumatic mating. Biological Reviews, 88, 585-601.

LAUTIE-HARIVEL, N. 1992. Drosophila C virus cycle during the development of two Drosophila melanogaster strains (Charolles and Champetieres) after larval contamination by food. Biol Cell, 76, 151-7.

LAUTIE-HARIVEL, N. \& THOMAS-ORILLARD, M. 1990. Location of Drosophila $C$ virus target organs in Drosophila host population by an immunofluorescence technique. Biol Cell, 69, 35-9. 
LEGGETT, H. C., CORNWALLIS, C. K. \& WEST, S. A. 2012. Mechanisms of pathogenesis, infective dose and virulence in human parasites. PLoS Pathog, 8, e1002512.

LEMAITRE, B. \& HOFFMANN, J. 2007. The host defense of Drosophila melanogaster. Annu Rev Immunol, 25, 697-743.

LEVINE, B., YOSHIMORI, T. \& DERETIC, V. 2009. Autophagy in infection and immunity, Dordrecht ; New York, Springer.

LI, H., LI, W. X. \& DING, S. W. 2002. Induction and suppression of RNA silencing by an animal virus. Science, 296, 1319-21.

LIEHL, P., BLIGHT, M., VODOVAR, N., BOCCARD, F. \& LEMAITRE, B. 2006. Prevalence of local immune response against oral infection in a Drosophila/Pseudomonas infection model. PLoS Pathog, 2, e56.

LINSER, P. J. \& DINGLASAN, R. R. 2014. Insect Gut Structure, Function, Development and Target of Biological Toxins. Insect Midgut and Insecticidal Proteins, 47, 1-37.

LIU, B., BEHURA, S. K., CLEM, R. J., SCHNEEMANN, A., BECNEL, J., SEVERSON, D. W. \& ZHOU, L. 2013. P53-mediated rapid induction of apoptosis conveys resistance to viral infection in Drosophila melanogaster. PLoS Pathog, 9, e1003137.

LONGDON, B., CAO, C., MARTINEZ, J. \& JIGGINS, F. M. 2013. Previous exposure to an RNA virus does not protect against subsequent infection in Drosophila melanogaster. PLoS One, 8, e73833.

LU, H. L. \& ST LEGER, R. J. 2016. Insect Immunity to Entomopathogenic Fungi. Genetics and Molecular Biology of Entomopathogenic Fungi, 94, 251-285.

LU, H. L., WANG, J. B., BROWN, M. A., EUERLE, C. \& ST LEGER, R. J. 2015. Identification of Drosophila Mutants Affecting Defense to an Entomopathogenic Fungus. Sci Rep, 5, 12350.

MAGWIRE, M. M., FABIAN, D. K., SCHWEYEN, H., CAO, C., LONGDON, B., BAYER, F. \& JIGGINS, F. M. 2012. Genome-wide association studies reveal a simple genetic basis of resistance to naturally coevolving viruses in Drosophila melanogaster. PLoS Genet, 8, e1003057.

MARTINS, N. E., FARIA, V. G., NOLTE, V., SCHLOTTERER, C., TEIXEIRA, L., SUCENA, E. \& MAGALHAES, S. 2014. Host adaptation to viruses relies on few genes with different cross-resistance properties. Proc Natl Acad Sci U S A, 111, 5938-43.

MARTINS, N. E., FARIA, V. G., TEIXEIRA, L., MAGALHAES, S. \& SUCENA, E. 2013. Host adaptation is contingent upon the infection route taken by pathogens. PLoS Pathog, 9, e1003601.

MERKLING, S. H., BRONKHORST, A. W., KRAMER, J. M., OVERHEUL, G. J., SCHENCK, A. \& VAN RIJ, R. P. 2015a. The epigenetic regulator G9a mediates tolerance to RNA virus infection in Drosophila. PLoS Pathog, 11, e1004692.

MERKLING, S. H., OVERHEUL, G. J., VAN MIERLO, J. T., ARENDS, D., GILISSEN, C. \& VAN RIJ, R. P. 2015b. The heat shock response restricts virus infection in Drosophila. Sci Rep, 5, 12758.

MERKLING, S. H. \& VAN RIJ, R. P. 2013. Beyond RNAi: antiviral defense strategies in Drosophila and mosquito. J Insect Physiol, 59, 159-70. 
MIEST, T. S. \& BLOCH-QAZI, M. 2008. Sick of mating: sexual transmission of a pathogenic bacterium in Drosophila melanogaster. Fly (Austin), 2, 215-9.

MISTRY, R., KOUNATIDIS, I. \& LIGOXYGAKIS, P. 2016. Exploring interactions between pathogens and the Drosophila gut. Dev Comp Immunol, 64, 3-10.

MOY, R. H., GOLD, B., MOLLESTON, J. M., SCHAD, V., YANGER, K., SALZANO, M. V., YAGI, Y., FITZGERALD, K. A., STANGER, B. Z., SOLDAN, S. S. \& CHERRY, S. 2014. Antiviral autophagy restrictsRift Valley fever virus infection and is conserved from flies to mammals. Immunity, 40, 51-65.

MUSSABEKOVA, A., DAEFFLER, L. \& IMLER, J. L. 2017. Innate and intrinsic antiviral immunity in Drosophila. Cell Mol Life Sci, 74, 2039-2054.

NAINU, F., TANAKA, Y., SHIRATSUCHI, A. \& NAKANISHI, Y. 2015. Protection of Insects against Viral Infection by Apoptosis-Dependent Phagocytosis. J Immunol, 195, 5696-706.

NAKAMOTO, M., MOY, R. H., XU, J., BAMBINA, S., YASUNAGA, A., SHELLY, S. S., GOLD, B. \& CHERRY, S. 2012. Virus recognition by Toll-7 activates antiviral autophagy in Drosophila. Immunity, 36, 65867.

NAYAK, A., BERRY, B., TASSETTO, M., KUNITOMI, M., ACEVEDO, A., DENG, C. H., KRUTCHINSKY, A., GROSS, J., ANTONIEWSKI, C. \& ANDINO, R. 2010. Cricket paralysis virus antagonizes Argonaute 2 to modulate antiviral defense in Drosophila. Nature Structural \& Molecular Biology, 17, 547-U41.

NEHME, N. T., LIEGEOIS, S., KELE, B., GIAMMARINARO, P., PRADEL, E., HOFFMANN, J. A., EWBANK, J. J. \& FERRANDON, D. 2007. A model of bacterial intestinal infections in Drosophila melanogaster. PLOS Pathog, 3, e173.

NEYEN, C., BRETSCHER, A. J., BINGGELI, O. \& LEMAITRE, B. 2014. Methods to study Drosophila immunity. Methods, 68, 116-28.

OSBORNE, S. E., ITURBE-ORMAETXE, I., BROWNLIE, J. C., O'NEILL, S. L. \& JOHNSON, K. N. 2012. Antiviral protection and the importance of Wolbachia density and tissue tropism in Drosophila simulans. Appl Environ Microbiol, 78, 6922-9.

ROULSTON, A., MARCELLUS, R. C. \& BRANTON, P. E. 1999. Viruses and apoptosis. Annu Rev Microbiol, 53, 577-628.

ROXSTROM-LINDQUIST, K., TERENIUS, O. \& FAYE, I. 2004. Parasitespecific immune response in adult Drosophila melanogaster: a genomic study. EMBO Rep, 5, 207-12.

RYU, J. H., HA, E. M., OH, C. T., SEOL, J. H., BREY, P. T., JIN, I., LEE, D. G., KIM, J., LEE, D. \& LEE, W. J. 2006. An essential complementary role of NF-kappaB pathway to microbicidal oxidants in Drosophila gut immunity. EMBO J, 25, 3693-701.

RYU, J. H., KIM, S. H., LEE, H. Y., BAI, J. Y., NAM, Y. D., BAE, J. W., LEE, D. G., SHIN, S. C., HA, E. M. \& LEE, W. J. 2008. Innate immune homeostasis by the homeobox gene caudal and commensal-gut mutualism in Drosophila. Science, 319, 777-82.

SALEH, M. C., TASSETTO, M., VAN RIJ, R. P., GOIC, B., GAUSSON, V., BERRY, B., JACQUIER, C., ANTONIEWSKI, C. \& ANDINO, R. 2009. 
Antiviral immunity in Drosophila requires systemic RNA interference spread. Nature, 458, 346-50.

SANCHEZ-VARGAS, I., SCOTT, J. C., POOLE-SMITH, B. K., FRANZ, A. W., BARBOSA-SOLOMIEU, V., WILUSZ, J., OLSON, K. E. \& BLAIR, C. D. 2009. Dengue virus type 2 infections of Aedes aegypti are modulated by the mosquito's RNA interference pathway. PLoS Pathog, 5, e1000299.

SANSONE, C. L., COHEN, J., YASUNAGA, A., XU, J., OSBORN, G., SUBRAMANIAN, H., GOLD, B., BUCHON, N. \& CHERRY, S. 2015. Microbiota-Dependent Priming of Antiviral Intestinal Immunity in Drosophila. Cell Host Microbe, 18, 571-81.

SHARON, G., SEGAL, D., RINGO, J. M., HEFETZ, A., ZILBERROSENBERG, I. \& ROSENBERG, E. 2010. Commensal bacteria play a role in mating preference of Drosophila melanogaster. Proc Natl Acad Sci U S A, 107, 20051-6.

SHELLY, S., LUKINOVA, N., BAMBINA, S., BERMAN, A. \& CHERRY, S. 2009. Autophagy is an essential component of Drosophila immunity against vesicular stomatitis virus. Immunity, 30, 588-98.

SIVA-JOTHY, M. T., MORET, Y. \& ROLFF, J. 2005. Insect immunity: An evolutionary ecology perspective. Advances in Insect Physiology, Vol $32,32,1-48$.

SPELLBERG, M. J. \& MARR, M. T., 2ND 2015. FOXO regulates RNA interference in Drosophila and protects from RNA virus infection. Proc Natl Acad Sci U S A, 112, 14587-92.

STEVANOVIC, A. L., ARNOLD, P. A. \& JOHNSON, K. N. 2015. Wolbachiamediated antiviral protection in Drosophila larvae and adults following oral infection. Appl Environ Microbiol, 81, 8215-23.

STEVANOVIC, A. L. \& JOHNSON, K. N. 2015. Infectivity of Drosophila C virus following oral delivery in Drosophila larvae. J Gen Virol, 96, 14906.

TABER, C. W. 2017. In: DONALD VENES, M., MSJ, FACP (ed.) Taber's Cyclopedic Medical Dictionary. 23 ed.: Davis Company.

TAJIRI, R. 2017. Cuticle itself as a central and dynamic player in shaping cuticle. Curr Opin Insect Sci, 19, 30-35.

TASSETTO, M., KUNITOMI, M. \& ANDINO, R. 2017. Circulating Immune Cells Mediate a Systemic RNAi-Based Adaptive Antiviral Response in Drosophila. Cell, 169, 314-325 e13.

TEISSIER, L. H. E. G. 1937. Une anomalie physiologique héréditaire chez la Drosophile. C.R. Acad. Sci. Paris, 231, 192-194.

TEIXEIRA, L., FERREIRA, A. \& ASHBURNER, M. 2008. The bacterial symbiont Wolbachia induces resistance to RNA viral infections in Drosophila melanogaster. PLoS Biol, 6, e2.

TENINGES, D., OHANESSIAN, A., RICHARDMOLARD, C. \& CONTAMINE, D. 1979. Isolation and Biological Properties of Drosophila X-Virus. Journal of General Virology, 42, 241-254.

THOMAS-ORILLARD, M. 1984. Modifications of Mean Ovariole Number, Fresh Weight of Adult Females and Developmental Time in DROSOPHILA MELANOGASTER Induced by Drosophila C Virus. Genetics, 107, 635-44. 
THOMAS-ORILLARD, M. 1988. Interaction between a picornavirus and a wild population ofDrosophila melanogaster. Oecologia, 75, 516-520.

THOMAS-ORILLARD, M. 1990. Paradoxical influence of an RNA virus on Drosophila host population. Endocytobiosis and Cell Research, 7, 97104.

TZOU, P., OHRESSER, S., FERRANDON, D., CAPOVILLA, M., REICHHART, J. M., LEMAITRE, B., HOFFMANN, J. A. \& IMLER, J. L. 2000. Tissue-specific inducible expression of antimicrobial peptide genes in Drosophila surface epithelia. Immunity, 13, 737-48.

VALE, P. F. \& JARDINE, M. D. 2015. Sex-specific behavioural symptoms of viral gut infection and Wolbachia in Drosophila melanogaster. J Insect Physiol, 82, 28-32.

VAN RIJ, R. P., SALEH, M. C., BERRY, B., FOO, C., HOUK, A., ANTONIEWSKI, C. \& ANDINO, R. 2006. The RNA silencing endonuclease Argonaute 2 mediates specific antiviral immunity in Drosophila melanogaster. Genes Dev, 20, 2985-95.

VATANSEVER, F., DE MELO, W. C. M. A., AVCI, P., VECCHIO, D., SADASIVAM, M., GUPTA, A., CHANDRAN, R., KARIMI, M., PARIZOTTO, N. A., YIN, R., TEGOS, G. P. \& HAMBLIN, M. R. 2013. Antimicrobial strategies centered around reactive oxygen species bactericidal antibiotics, photodynamic therapy, and beyond. Fems Microbiology Reviews, 37, 955-989.

VODOVAR, N., VINALS, M., LIEHL, P., BASSET, A., DEGROUARD, J., SPELLMAN, P., BOCCARD, F. \& LEMAITRE, B. 2005. Drosophila host defense after oral infection by an entomopathogenic Pseudomonas species. Proc Natl Acad Sci U S A, 102, 11414-9.

WAGNER, C., ISERMANN, K., FEHRENBACH, H. \& ROEDER, T. 2008. Molecular architecture of the fruit fly's airway epithelial immune system. BMC Genomics, 9, 446.

WANG, X. H., ALIYARI, R., LI, W. X., LI, H. W., KIM, K., CARTHEW, R., ATKINSON, P. \& DING, S. W. 2006. RNA interference directs innate immunity against viruses in adult Drosophila. Science, 312, 452-4.

WERREN, J. H., BALDO, L. \& CLARK, M. E. 2008. Wolbachia: master manipulators of invertebrate biology. Nat Rev Microbiol, 6, 741-51.

WHO. 2016. Vector-borne diseases [Online]. Available: http://www.who.int/mediacentre/factsheets/fs387/en/.

WONG, Z. S., BROWNLIE, J. C. \& JOHNSON, K. N. 2016. Impact of ERK activation on fly survival and Wolbachia-mediated protection during virus infection. J Gen Virol, 97, 1446-52.

XU, J., HOPKINS, K., SABIN, L., YASUNAGA, A., SUBRAMANIAN, H., LAMBORN, I., GORDESKY-GOLD, B. \& CHERRY, S. 2013. ERK signaling couples nutrient status to antiviral defense in the insect gut. Proc Natl Acad Sci U S A, 110, 15025-30.

YE, Y. H., SELEZNEV, A., FLORES, H. A., WOOLFIT, M. \& MCGRAW, E. A. 2017. Gut microbiota in Drosophila melanogaster interacts with Wolbachia but does not contribute to Wolbachia-mediated antiviral protection. J Invertebr Pathol, 143, 18-25.

ZAMBON, R. A., NANDAKUMAR, M., VAKHARIA, V. N. \& WU, L. P. 2005. The Toll pathway is important for an antiviral response in Drosophila. Proc Natl Acad Sci U S A, 102, 7257-62. 
ZAMBON, R. A., VAKHARIA, V. N. \& WU, L. P. 2006. RNAi is an antiviral immune response against a dsRNA virus in Drosophila melanogaster. Cell Microbiol, 8, 880-9.

ZHONG, W., MCCLURE, C. D., EVANS, C. R., MLYNSKI, D. T., IMMONEN, E., RITCHIE, M. G. \& PRIEST, N. K. 2013. Immune anticipation of mating in Drosophila: Turandot $\mathrm{M}$ promotes immunity against sexually transmitted fungal infections. Proc Biol Sci, 280, 20132018. 